\title{
Juventude, educação e cidadania: os desafios da participação social e política
}

\author{
Youth, education and citizenship: the challenges of social and \\ political participacion
}

\section{Jaime José Zitkoski \\ Lúcio Jorge Hammes}

\section{Resumo}

Este artigo tem como objetivo refletir sobre as relaçóes entre juventude, participação política e educação para a cidadania. Sabe-se que a juventude não se constitui em um bloco uniforme e precisa ser compreendida nas suas particularidades. Hoje, a juventude se constitui em um grupo expressivo, capaz de exercer pressão social e influenciar a agenda política. Nessa perspectiva, buscaremos discutir a seguinte questão: a mobilização política e social dos jovens na atualidade tem o potencial de produzir transformaçóes efetivas nas estruturas socialmente constituídas? Focalizaremos a análise na participação cidadã protagonizada pela juventude a partir das mobilizações populares e sociais vivenciadas no Brasil a partir de junho de 2013. Para abordar esse contexto sociopolítico atual, retomamos alguns aspectos relevantes da história recente de organização da juventude em grupos vinculados às Igrejas, organizaçóes não governamentais e movimentos sociais.

\section{Palavras-chave}

Juventude; Educação; Participação; Cidadania.

\begin{abstract}
This article aims to analyze the relationship between youth, political participation and citizenship education. It is known that youth does not constitute a uniform block and needs to be understood in terms of its particularities. Today, youth constitutes a significant group capable of pressuring and influencing the political agenda. In this perspective, we discuss the following question: social and political mobilization of young people today have the potential to produce effective changes in structures socially formed? We focus our analysis on citizen participation carried out by youth from the popular and social movements experienced in Brazil from June 2013. To address this current sociopolitical context, we resumed some relevant aspects of the recent history of organizing youth groups linked to the Churches, Non-Governmental Organizations and social movements.
\end{abstract}

\section{Keywords}

Youth; Education; Participation; Citizenship. 


\section{Introdução}

Segundo Krauskopf (2000), a construção da cidadania juvenil é um tema estratégico de nosso tempo, face à expressão numérica da juventude no mundo, pois a juventude se constitui um grupo expressivo, capaz de exercer pressão social ${ }^{1}$. Schwartz (1995) já alertava para o impacto dessa população jovem, com consequências no desenvolvimento de novos cenários sociais. A presença da juventude sua força matriz impõem desafios à educação, no sentido de entender as mudanças nos padrões de seu comportamento. Dessa forma, uma educação política do jovem voltada para a construção de uma cidadania ativa constitui-se em desafio central nestas sociedades.

Analisando as pesquisas sobre juventude e os temas emergentes, Spósito e Corti (2002) reconhecem a necessidade de um redimensionamento do foco das investigaçôes, produzindo maior amplitude no tratamento do sujeito e sugerem uma perspectiva mais próxima do jovem, investigando os novos padróes culturais. Nas palavras das autoras, "não se trata apenas do aluno, mas de desvelar o jovem, contribuindo, assim, para que o conhecimento avance no sentido de produzir informaçôes sobre as várias faces que envolvem sua condição" (SPÓSITO e CORTI, 2002, p. 205).

Em face disso, este artigo procura olhar os jovens livres da postura de desqualificação, como sujeitos capazes de açôes propositivas e interlocutores para decifrar conjuntamente, mesmo que conflituosamente, o significado das tendências sociais do nosso tempo e das saídas e soluçóes para elas. Tal perspectiva pode ajudar a compreender melhor a participação dos jovens brasileiros e as mobilizaçóes populares em junho de 2013, lideradas pelo movimento do Passe Livre e a articulação do Bloco de Lutas. Dessa maneira, entendem-se melhor os jovens que buscam ser protagonistas nos dias de hoje. Freire, descrevendo o movimento da juventude de 1968, também destaca o sentido antropológico de uma época:

\footnotetext{
${ }^{1}$ Segundo este relatório, vivemos em um mundo jovem, com quase metade da população mundial com idade inferior a 25 anos, totalizando 1,2 bilhão de jovens, o que requer a atenção e foco para esta faixa de população (UN, 2005).
} 


\begin{abstract}
Os movimentos de rebelião, sobretudo de jovens, no mundo atual, que necessariamente revelam peculiaridades dos espaços onde se dão, manifestam, em sua profundidade, esta preocupaçâo em torno do homem e dos homens como seres no mundo e com o mundo. Em torno do que e de como estão sendo. Ao questionarem a "civilização do consumo"; ao denunciarem as "burocracias" de todos os matizes; ao exigirem a transformação das universidades, de que resulte, de um lado, o desaparecimento da rigidez nas relaçóes professor-aluno; de outro, a inserção deles na realidade; ao proporem a transformação da realidade mesma para que as universidades possam renovar-se; ao rechaçarem velhas ordens e instituiçóes estabelecidas, buscando a afirmação dos homens como sujeitos de decisão, todos estes movimentos refletem o sentido mais antropológico do que antropocêntrico de nossa época (FREIRE, 1993, p. 29).
\end{abstract}

Neste texto, buscaremos compreender a participação social e política dos jovens da segunda metade do século XX e início do século XXI. São formas de participaçáo com características específicas e diferentes em cada período, sociedades e culturas políticas próprias. Temos como universo de análise a participação dos jovens em açóes populares (como no movimento do Passe Livre, dentre outros) e uma pesquisa desenvolvida na Unisinos (HAMMES, 2005) em que foram desenvolvidas entrevistas junto a diversas organizações juvenis (Pastorais de juventude; jovens do Movimento dos Sem Terra e jovens de uma Organização Não-Governamental em prol da cultura da paz). Os dados serão analisados com referência teórica e leituras de outras pesquisas e autores que tratam da temática sobre a formação da cidadania.

$\mathrm{O}$ artigo discute na primeira parte a formação para a cidadania e as formas clássicas de participação dos jovens, destacando uma educação dialógica e participativa, uma educaçáo conectada com o mundo dos jovens, propostas para uma educação comprometida com a cidadania juvenil e a cidadania e participação política dos jovens. Na segunda parte, analisa as novidades em relação a participação política nas mobilizaçóes lideradas pelos jovens hoje e, na terceira parte, apresenta alguns desafios para a construção do novo na história em relação à cidadania e à participação.

\title{
A formação para a cidadania e as formas clássicas de participação dos jovens
}

A conclusão da pesquisa sobre os "Aprendizados de convivência e a formação de capital social: um estudo sobre grupos juvenis” (HAMMES, 2005) revelam processos educativos de natureza não formal, desenvolvidos em grupos juvenis, 
vinculados à Rede Em Busca da Paz $(\mathrm{EBP})^{2}$, à Pastoral da Juventude Estudantil $(\mathrm{PJE})^{3}$ e ao Movimento dos Sem Terra $(\mathrm{MST})^{4}$. Os resultados indicam que a escolarização é um espaço privilegiado de educação da juventude, pois, além de ser um espaço de ensino-aprendizagem, propicia o intercâmbio juvenil e favorece o surgimento de uma cultura típica e um jeito próprio de ser jovem.

Com a finalidade de conhecer a proposta de educação sugerida pelos entrevistados que participam ou participaram da experiência de grupo, foi perguntado: "O que você sugere para a educação dos jovens de hoje?". Nas respostas, os entrevistados destacaram a importância "de o jovem ser sujeito de sua formação", possibilitando o novo, com experiência para além da sala de aula. Afirmaram que uma das questóes centrais para uma a educação de qualidade é "valorizar o jovem como jovem" e revelaram que "a educação deve se abrir e valorizar o jovem como pessoa e não só como alguém que deve aprender” (MELO, 2004) 5 . Valorizar o jovem enquanto jovem e como sujeito de seu processo de formação implica, por sua vez, que a educação tenha presente a situação concreta das pessoas.

\footnotetext{
${ }^{2}$ A Rede Em Busca da Paz constituiu-se em uma ONG voltada para a construção de uma cultura de paz, de promoção dos direitos humanos e assume a não-violência como estilo de vida e metodologia de ação. O grupo pesquisado desta organização foi Jovens Unidos Pela Paz (JUPA) de Santa Cruz do Sul.

3 A Pastoral da Juventude Estudantil é organizada por, com e para os estudantes do Ensino Fundamental e Médio, para que desempenhem a missão: "construir uma sociedade justa e fraterna, buscando transformaçóes a partir da sala de aula".

${ }^{4}$ O Movimento dos Sem Terra surge em função da reforma agrária no dia 07 de setembro de 1979 , em Ronda Alta (RS). Está presente em praticamente todo o Brasil e organiza mais de 1,5 milhão de pessoas em acampamentos e assentamentos. Os jovens entrevistados foram do assentamento da Fazenda Quinta de Encruzilhada do Sul.

${ }^{5}$ Neste artigo os nomes serão fictícios para preservar a identidade dos sujeitos entrevistados.
} 


\begin{abstract}
A grande questão hoje é a violência. O que fazer? Muitas crianças têm problemas sérios e os professores não estão dando conta. Quando a criança está mal humorada, o professor tenta uma vez e se não consegue resultados, deixa para lá. Mas não é assim que as coisas devem ser tratadas. $\mathrm{O}$ trabalho com as crianças a partir do grupo mostrou que as crianças também têm dificuldades de se abrir e, quando conseguimos chegar até elas acontecem maravilhas. Claro, também os pais têm dificuldades de compreender as crianças e os jovens. Daí se torna violentas, porque não tem saídas. É isso que vemos na TV. É filho que mata o pai, filha mata o pai e não ter remorso. $\mathrm{Na}$ experiência de grupo aprendemos a valorizar as pessoas: crianças, colegas, familiares... Acho que o grande problema na educação é a carência, a falta do diálogo, desconectada com a situação dos jovens e autoritárias. No grupo se pode perceber as fraquezas e trabalhar isso com os colegas (GARCIA, 2004).
\end{abstract}

Considerando os aspectos centrais das falas dos jovens entrevistados na pesquisa junto à juventude, pode-se considerar que as principais demandas reivindicadas pela juventude hoje em relaçáo à educação escolar e suas relaçóes com a sociedade, à participação política e à formação para a cidadania estâo contempladas nos quatro pontos que analisamos abaixo.

\title{
a) Uma educação dialógica e participativa
}

A proposta de uma participação cidadã está sempre presente nos depoimentos dos jovens a partir da valorização do diálogo entre todos os sujeitos da educação. Especialmente para os responsáveis, professores ou direção, os entrevistados sugeriram "escutar os jovens e dar oportunidade para que eles participem. Acho que a educação deve ser adequada para a juventude" (GARCIA, 2004). Nessa perspectiva, as falas dos jovens dialogam com as propostas pedagógicas da Escola Cidadâ inauguradas por Paulo Freire em 1989, quando atuou como secretário da educação na cidade de São Paulo.

Para Freire (1993), a relação dialógica entre educador e educando facilita o processo de construção do conhecimento, que exige o movimento dos diferentes saberes de todo um grupo e a construção de relações horizontais entre as pessoas.

\footnotetext{
${ }^{6}$ O Projeto da Escola Cidadã teve origem no paradigma da Educação Popular, que evoluiu a partir da década de 1990 de experiências pontuais de propostas de educação informal para o desafio de transformar a escola pública voltada para os interesses e necessidades autênticos da população que a frequenta, constituída basicamente dos filhos das classes populares.
} 
Todos precisam sentir-se livres e autônomos para discordar, opor-se, sugerir e ressignificar suas práticas sociais.

Em uma escola democrática, precisamos criar mecanismos institucionais de inclusão capazes de romper com a padronização do ensino e garantir o apoio necessário para que todos aprendam, principalmente, a construírem-se de forma autônoma, socialmente emancipada e cidadá. A construção da autonomia admite a diferença e, por isso, supóe a parceria. Só a igualdade na diferença e o comprometimento coletivo são capazes de criar um "novo" ser humano, mais humanizado, solidário e socialmente responsável. Por isso, escola autônoma náo significa escola isolada, mas em constante integração com a sociedade.

A Escola Cidadã é uma alternativa ao modelo de escola burocrática que ainda se impõe de forma hegemônica. É fundamental, hoje, dar um novo sentido à função social da educação escolar e da práxis de todos os sujeitos envolvidos: educadores, pais, educandos, direção de escola e da comunidade local. O princípio da gestão democrática e da autonomia requer a organização e consolidação dos Conselhos Escolares que participam na tomada de decisóes pedagógicas e administrativas da escola, usando de seu direito deliberativo.

As propostas de uma educação escolar comprometida com a cidadania dos jovens tem um caráter social comunitário, pois a escola é um espaço público para elaborar nova cultura, reconstruindo saberes significativos à comunidade escolar através do processo dialético entre diferentes tipos de saberes (científico, popular, religioso, artístico, filosófico, entre outros).

O respeito ao saber popular implica, necessariamente, o respeito ao contexto cultural. A localidade dos educandos é o ponto de partida para o conhecimento que eles vão criando do mundo. E seu mundo, em última análise, é a primeira e inevitável face do mundo mesmo (FREIRE, 1993 , p. 86).

Dessa forma, a valorização dos diversos saberes e da participação de toda comunidade escolar envolvendo os alunos, professores e funcionários na gestão de um novo projeto educacional proporcionará um melhor funcionamento da escola, com relações mais humanizadas de quem nela convive. Esse processo de diálogo oportuniza a produção de conhecimentos mais significativos para a vida dos educandos, além da emancipaçáo e afirmação da autonomia dos sujeitos que em torno da escola circulam. 


\section{b) Uma educação conectada com o mundo dos jovens}

Apareceu com bastante ênfase nas falas dos jovens, também, a sugestão de "possibilitar que os jovens façam outras experiências de vida", além da sala de aula, para além das disciplinas ou do dever ser. Segundo os entrevistados:

A educação deveria se voltar mais para a pessoa. E, além das disciplinas normais, deveria ter espaço para que a juventude pudesse ter uma orientação para a vida, um caminho certo a tomar. Tipo um conselho de como levar a vida (GOMES, 2004).

Sugiro ousar e ir contra o "dever ser". Formular curriculo "com", fazer caminho "com" os alunos. Eles sim são capazes! Sim, tem coisas interessantes. São coisas que a educação formal pode aprender com a PJ. Valorizar, propor outras dinâmicas. Ao mesmo tempo acredito que a revolução acontece no provisório. Não no instituído. Neste sentido sou de que a PJ deve continuar no caráter de provisoriedade. A gurizada gosta de estar no grupo porque é outra coisa e não o institucional. É fundamental para os jovens. Também porque retroalimenta a outra experiência - a formal. Propicia outros olhares sobre a formação. Entendo o grupo como um espaço importante para na formação da juventude (SCHMIDT, 2004).

Os jovens reivindicam, com razão, uma educação mais interdisciplinar, que esteja em diálogo com o mundo concreto em que vivem. Nessa perspectiva, segundo Freire (1993), podemos conceber que a interdisciplinaridade é o caminho mais coerente para trabalhar com as realidades humanas e sociais contemporâneas, pois prioriza o estudo das relaçóes entre sujeitos e destes com o mundo e uma formação mais crítico-humanizadora das pessoas. $\mathrm{O}$ caminho que se coloca para a cidadania dos jovens hoje é o diálogo entre as diferentes modalidades de saberes, para que na prática possamos formar cidadãos comprometidos com práticas sociais humanizadoras. A partir desse horizonte, podemos entender que o conhecimento, a ciência e a educação só tem sentido se contribuírem com o Ser Mais da humanidade toda. Portanto, a educação escolar requer um compromisso ético político diante das demandas dos jovens que alimentam a esperança por um mundo mais justo e digno para vivermos.

Nesse sentido, os jovens destacaram a experiência de grupo como parâmetro importante para a formação da juventude que, segundo eles, "poderia ser levada para a sala de aula": 
Eu vejo que a experiência de grupo pode ser levada para a sala de aula. Aproveitar esta metodologia para desenvolver a formação também na sala de aula. Acho que dá para desgrudar um pouco dos conteúdos - que não só servem para passar no vestibular - e insistir na formação da pessoa como um todo. Pois eu acredito que uma formação humana consistente ajuda a buscar desenvolver conteúdos necessários para o desenvolvimento profissional. Aliás, acredito que hoje é mais importante insistir na formação humana do que a formação técnica e conteudista, talvez para contrapor a supervalorização do conteúdo dos dias de hoje (GERHART, 2004).

Uma educação de qualidade, segundo os entrevistados, deveria ser “encarnada" na realidade. Por isso, é fundamental aos educadores “interessarem-se pela comunidade e trazer a vida do jovem para dentro da sala de aula”. Dois entrevistados afirmaram desse modo:

1)Sugiro participar das coisas. Interessar-se pela comunidade. Fazer algo de bom também para o outro (SCHMIDT, 2004).

2)Eu acredito que a educação ideal deva privilegiar a convivência entre as pessoas. Valorizar as experiências de vida dos estudantes. Ele não é tábua lisa que não sabe nada e deve ser ensinado. Ele já tem experiência de vida. Desenvolver o ensino a partir da própria vida do jovem. Trazer a vida do jovem para dentro da sala de aula. E propiciar que o jovem desenvolva outros aprendizados, para além da sala de aula (ARNOLD, 2004).

As respostas dos entrevistados indicaram que a formação cidadã envolvia conhecimentos e habilidades cívicas, predisposições e atitudes em relação à participação social e política, crenças e valores em relação à democracia em si. Portanto, essa formação tem a ver, não só para a prática educacional, mas também para a participação social mais ampla. Segundo Baquero (1997), o esgotamento da análise política direcionada às explicações de natureza macro, no que diz respeito à construção e consolidação democrática de uma sociedade, tem levado os pesquisadores a voltarem seus interesses para o estudo do cidadáo e o processo de desenvolvimento de sua personalidade política, através do processo de socialização. 


\section{c) Propostas para uma educação comprometida com a cidadania juvenil}

Segundo as propostas da Escola Cidadã, o grande desafio de toda e qualquer instituição escolar é formar para a cidadania e, para isso, o ambiente escolar deve ser o exemplo de democracia e participação cidadã. Assim, a gestão democrática da escola é um passo importante no aprendizado da democracia. Nesse sentido, a escola deve ser aberta e estar a serviço da comunidade através de uma gestáo que envolva todos os setores interessados no sucesso da educação e contemple a cultura, a realidade e o mundo vivido da população que constitui seu entorno, com seus saberes, lutas, conquistas, desafios, incertezas, esperanças e anseios por uma vida mais digna e feliz para todos.

Certamente, a participação da comunidade, dos alunos, dos professores e dos funcionários na gestão de um novo projeto educacional proporcionará um melhor funcionamento da escola, com relações mais humanizadas de quem nela convive e com produção de conhecimentos mais significativos para a vida dos educandos, além da emancipação e afirmação da autonomia dos sujeitos sociais que em torno dela gravitam.

Formar na perspectiva da cidadania é, portanto, a afirmaçáo do valor da educação como espaço público onde a construção do conhecimento está a serviço da produção de valores emancipatórios, libertadores, formadores de sujeitos históricos, críticos e conscientes, capazes de conquistar e exercer a cidadania. Ela está comprometida com o sucesso de seus alunos e objetiva a inclusão de todos através de um ensino de qualidade, de uma formação cultural democrática e solidária via a formação dos educandos em todas as dimensóes de sua existência.

Por sua característica de relação humana, a educação só pode dar-se mediante o processo pedagógico, necessariamente dialógico, não dominador, que garanta a condição de sujeito tanto do educador quanto do educando. Por sua imprescindibilidade para a realização históricohumana, a educação deve ser direito de todos os indivíduos enquanto viabilizadora de sua condição de seres humanos (PARO, 2000, p.8).

Segundo Gadotti (1994), a cidadania e a autonomia são, na atualidade da vida social, duas categorias estratégicas e indispensáveis na construção de uma sociedade democrática e emancipada. Essa base cultural precisa ser formada em nossa sociedade para que tenhamos uma identidade nacional comprometida com um projeto de país em sintonia com a realidade de seu povo, superando o individualismo 
das elites e a cultura paternalista de um Estado que se preocupa apenas com o assistencialismo para manter privilégios e administrar a profunda crise social. $\mathrm{O}$ movimento atual da chamada Escola Cidadá, está inserido nesse contexto de novos desafios para a educação brasileira e sua colaboração para construir um novo projeto de sociedade.

Como uma rede de intercâmbio de ideias e experiências práticas concepções educacionais, o Instituto Paulo Freire ${ }^{7}$ contribui para o desenvolvimento da educação humanista-libertadora, difundindo conhecimentos e formando grupos de trabalhos que atuam em projetos inovadores de gestáo escolar, formação continuada de professores, atendimento aos educandos e preparação dos funcionários. E o projeto da Escola Cidadã é uma das frentes de atuação do Instituto Paulo Freire em vários países mundo afora.

Segundo as propostas da Escola Cidadã, o grande desafio de toda e qualquer instituição escolar é formar para a cidadania e, para isso, o ambiente escolar deve ser o exemplo de democracia e participação cidadã. Assim, a gestão democrática da escola é um passo importante no aprendizado da democracia. Nesse sentido, a escola pode organizar-se de forma aberta e estar a serviço da comunidade através de uma gestão que envolva todos os setores interessados no sucesso da educação e contemple a cultura, a realidade e o mundo vivido da população que constitui seu entorno, com seus saberes, lutas, conquistas, desafios, incertezas, esperanças e anseios por uma vida mais digna e feliz para todos, em outras palavras, promover a participação ativa dos jovens em atividades políticas e comunitárias que produzam capital social.

\section{d) Cidadania e participação politica dos jovens}

Os estudos sobre capital social têm ampliado o conceito de cidadania e participaçáo política. Destacam-se as associaçóes e redes de solidariedade e cooperação recíproca. Putnam (1996, p. 177) define capital social como "características da organização social, como confiança, normas e sistemas, que contribuam para aumentar a eficiência da sociedade, facilitando as açóes coordenadas”. Preocupa-se em encontrar formas de regenerar a saúde política da sociedade, dando primazia para o

\footnotetext{
${ }^{7}$ Nessa direção, o projeto da Escola Cidadã tem sua raiz no Instituto Paulo Freire, fundado em 1992 em São Paulo, com a participação e colaboração direta do próprio educador que inspirou sua organização. O Instituto Paulo Freire é uma rede de pessoas e instituiçóes com membros distribuídos em quinze países, que tem por objetivo pesquisar, sistematizar e divulgar dados, experiências inovadoras, reflexôes e informaçôes no campo da educação, cultura e organização de movimentos sociais emancipatórios.
} 
papel das normas, com valores coletivos. Segundo o autor, a confiança lubrifica a vida social, que é alcançada quando há um conhecimento mútuo entre os membros de uma comunidade. "Os sistemas de participação cívica são uma forma essencial de capital social: quanto mais desenvolvidos forem esses sistemas numa comunidade, maior será a probabilidade de que seus cidadãos sejam capazes de cooperar em benefício mútuo" (PUTNAM, 1996, p. 182).

Desse modo, o desenvolvimento de pesquisas pode ajudar na construção de um quadro analítico de referência para compreender como se dá o processo de constituição da cidadania juvenil. Por esta perspectiva, Krauskopf (2000), analisando a questão da participação social da juventude, chama a atenção para as mudanças provocadas pela globalização e a modernização, referindo, assim como Abramo (1997), que as políticas e programas de juventude necessitam considerar, como eixos estratégicos, a visibilização positiva dos jovens e a sua participação protagônica, abandonando o adultocentrismo, tendo presentes as diversas situaçóes de exclusão.

Segundo a autora, a mudança paradigmática se revela em diferentes dimensôes relacionadas com a participação juvenil: a constituição das identidades coletivas passa de parâmetros socioeconômicos e políticos-ideológicos para éticoexistenciais, com a orientação da transformação pessoal como estratégia para influenciar mudanças nas condições da vida coletiva e a atuação local para atingir mudanças globais, com metas palpáveis a curto e médio prazo em estruturas horizontais, flexíveis que respeitem a diversidade e a participação de todos (KRAUSKOPF, 2000, p. 129).

Rodríguez (2003) constata fenômenos de exclusão e desigualdade social presentes entre os grupos etários, resultando na marginalização dos jovens (sobretudo dos mais jovens) e dos idosos. Segundo esta pesquisadora, a participação e o empoderamento permitiriam criar consciência do público e do coletivo e, sobretudo, habilitariam para a criação de relaçóes de confiança que constroem e fortalecem as instituições. Conforme Rodríguez (2003):

Las generaciones jóvenes constituyen grupos claves en la construcción de capacidades para la gestión del desarrollo, tanto por sus características particulares, como por la posibilidad de tener un efecto hacia atrás y hacia adelante en la multiplicación de una visión diferente, de manera intergeneracional. Esto los convierte en sujetos de política de formación de capital social para el desarrollo (RODRÍGUEZ, 2003, p. 23).

Com a participação cidadã direta da juventude e a organização de novas formas de fazer política, entre os jovens, rompendo com o esquema clientelista, 
desenvolvem-se também capacidades de gestão cidadã, pela experiência acumulada de participação. Estas experiências são "caldo de cultivo de nuevas actitudes proclives al reconocimiento y respeto entre generaciones, porque abren posibilidades para la toma de perspectiva y el acceso a espacios de comunicación" (RODRÍGUEZ, 2003, p. 24).

\section{As mobilizações lideradas pelos jovens hoje: o que há de novo na participação politica?}

Após analisar as formas de organização que caracterizaram os movimentos juvenis que têm o grupo como base para sua organizaçáo, principalmente, retomando as formas clássicas de participação, queremos nos deter aos fenômenos recentes das mobilizaçóes de rua e nas formas de organização a partir das redes sociais.

Em nível internacional, as manifestações de rua e ocupação das praças públicas lideradas por jovens começaram no que se batizou como a "Primavera Árabe". No final de 2012 os jovens de vários países do norte do continente africano e da região do Oriente Médio se organizaram a partir das redes sociais, principalmente, utilizando os recursos da internet, tais como: facebook, e-mails, etc. Esse movimento social e político ficou conhecido e atingiu resultados surpreendentes em poucas semanas, pois derrubou ditadores que governavam há décadas países como o Egito, Líbano, Iêmen e Tunísia. Após os protestos liderados pelos jovens, outros grupos sociais somaram-se aos protestos e a pressão popular exigiu mudanças políticas que convergiram para eleições, mudanças de governo e uma nova agenda para vários países dessas regióes, que até então eram muito fechadas e resistentes a mudanças políticas.

No Brasil, as mobilizaçóes lideradas pelos jovens que se organizaram a partir das redes sociais tiveram e têm destaque em Porto Alegre, nos primeiros meses de 2013, embora tivessem mobilizaçóes pelo passe livre em anos anteriores em Florianópolis e São Paulo. As reivindicações em princípio giravam em torno da melhoria no transporte público e na diminuição do preço das passagens. Depois de várias manifestações nas ruas da capital gaúcha, onde a repressão policial e a visão preconceituosa da mídia tentou dispersar os jovens e desarticular as mobilizaçôes, outras cidades brasileiras tiveram grandes manifestações nas ruas com milhares de pessoas marchando e protestando contra vários problemas sociais da sociedade brasileira. Nesse cenário, destaca-se que o movimento denominado Passe Livr ${ }^{8}$

\footnotetext{
${ }^{8}$ Conforme Liberato (2006), o Movimento Passe-Livre (MPL) teve um primeiro momento de articulação como movimento nacional em janeiro de 2004, durante o V Fórum Social Mundial em Porto Alegre. Foi fundado a partir de grupos e coletivos que pautavam a luta pelo passe livre estudantil em várias cidades brasileiras. Em 2011 os estudantes do Distrito Federal, onde o MPL sempre esteve
} 
liderou grandes manifestações na cidade de São Paulo e vários movimentos de jovens também se organizaram pelas redes sociais e sacudiram a cidade de Rio de Janeiro, Vitória e Belo Horizonte.

Dessa forma, as manifestações e protestos de rua foram crescendo e atingindo uma reação em rede em importantes cidades de regiôes metropolitanas em todo Brasil e cidades pequenas também tiveram uma agenda significativa com jovens nas ruas dizendo o que pensam e desejam para o futuro. No mês de junho de 2013, o Brasil foi sacudido por uma grande onda de manifestaçóes populares que, por razóes do conjunto de temas reclamados pelos jovens e pela dimensão que atingiu em termos de número de participantes, passaram a colocar uma nova agenda política para os governos municipais, estaduais e, também, pelo governo federal. Foi a primeira vez que alguns problemas sociais começaram a ser debatidos pelas três esferas da gestão pública em nosso país.

Alguns saberes podem ser destacados nesse processo de mobilização popular liderados pelos jovens, embora acontecimentos recentes permitam que desmistifiquem algumas leituras conservadoras e pessimistas, que consideravam os jovens de hoje mergulhados na lógica consumista e alienados das questóes políticas e sociais. Ao contrário, os jovens estão mostrando que se preocupam com o futuro e tem grande capacidade de organização e de mobilização para colocar novos temas na agenda política de suas cidades, regióes e países. Nesse sentido, destacamos a seguir que:

1. No atual cenário mundial, início de século XXI, muitos câmbios sociopolíticos estão em curso, além de tantos outros que se delineiam para um futuro próximo. Portanto, no âmbito prático do campo político se impóe o desafio à sociedade civil organizada e, consequentemente, aos movimentos sociais e organizaçóes juvenis, da reinvenção do poder (FREIRE, 1994; SANTOS, 2007), desde os múltiplos espaços sociais, até às instâncias institucionalizadas hoje vigentes.

bem atuante, conquistam o passe livre no transporte. Em 2013 MPL ganha destaque na grande imprensa e a Tarifa Zero passa a ser tema de ampla discussão política após as grandes manifestações ocorridas em junho no país, as quais tiveram em grande parte como origem a mobilização do MPL de São Paulo para barrar o aumento das passagens de transporte coletivo na cidade. Ao fim de junho de 2013 mais de 100 cidades do país haviam reduzido a tarifa do transporte, em consequência das manifestaçóes. 
2. Um dos maiores desafios práticos na atualidade política, para todas as formas de mobilização popular que se quer progressista, é a reinvenção da democracia moderna (FREIRE, 1994) em seu modelo de democracia representativa. A complexidade dos sistemas sociais modernos e a dimensão populacional, principalmente os aglomerados urbanos, produz cada vez maior distância entre a classe política e a sociedade civil. Esse fator está causando um verdadeiro ciclo da opressão nas sociedades contemporâneas a partir do qual se efetivam os interesses de uma minoria que, apropriando-se dos aparelhos políticos através das estratégias do poder econômico e da mídia, governam a sociedade segundo seus planos de manutenção e ampliação do poder econômico e político. A consequência direta desse fenômeno é a atual dependência e/ou atrelamento dos Estados Nacionais ao mercado econômico globalizado que dita as regras para a política e passa a definir os destinos de milhóes de seres humanos segundo os critérios do lucro e da garantia de concentração das riquezas.

3. Os jovens, através das manifestações de rua e protestos contra o descaso dos "políticos tradicionais" (eleitos via a democracia representativa), constituem-se enquanto força política alternativa de transformação social. Mas, para que esse processo seja efetivo, os jovens e todos os setores da sociedade que se mobilizam em protestos de rua, necessitam pautar em suas manifestações, de modo estratégico, a recriação dos atuais modelos políticos que constituem a democracia meramente representativa. Pois nas sociedades atuais impóe-se a necessidade de alçar a política a outros níveis de organização da esfera pública, que superem o atual círculo viciado da democracia representativa, reinventando outras formas de fazer política, que não estão contempladas pelo sistema democrático vigente.

4. Para superar os aspectos meramente formais da democracia representativa, que apenas confere direitos legais dos cidadáos pertencentes à determinada organização social, mas exclui grande parcela da população do acesso àquilo que lhe é de direito, faz-se necessária a organização da sociedade civil em níveis condizentes com as atuais exigências de reestruturação do Estado e da política contemporânea, através do controle público dos mesmos (DEMO, 1993; SANTOS, 2007). Ou seja, é fundamental que os movimentos instituintes tencionem o que já está 
instituído para que no futuro próximo possamos ter mecanismos concretos de controle público das questôes centrais da vida pública, tais como: verbas públicas e investimentos, quais seriam as prioridades nos serviços públicos e qual a vontade e decisão da população nos temas mais sensíveis da vida pública.

5. Para avançarmos na implementação de Políticas Públicas voltadas aos serviços de atendimento de massa (transporte, educação, saúde e segurança) é fundamental que as diferentes esferas de governo trabalhem conjuntamente. No caso brasileiro, é grande a desarticulação e descompasso das três esferas da gestão pública no que tange ao funcionamento dos serviços públicos. Esse foi, segundo várias leituras, um dos principais focos de indignação pautados pelas mobilizações dos jovens em junho de 2013.

Diante desses desafios levantados pelas mobilizaçóes de rua que emergiram na vida pública recente no Brasil se impóe a tarefa de um amplo debate público entre a sociedade civil, partidos políticos e poderes instituídos. Portanto, um dos maiores desafios para o futuro de nossa cultura política é o de romper com os vícios do assistencialismo, acomodação e distanciamento da população no debate público e promover, gradativamente, uma intensa mobilização social diante dos problemas sociais mais dramáticos da sociedade brasileira, tais como: exclusão social, violência contra os mais fragilizados, abandono da infância, crise das instituiçôes públicas, precariedades dos serviços públicos, preconceitos contra as diferenças, etc.

A realização de uma ampla mobilização da sociedade brasileira é algo possível se considerarmos a realidade prática em que o povo vive no seu cotidiano. $\mathrm{O}$ despertar da populaçáo afetada pelos graves problemas sociais, que se sente desafiada mais diretamente pela dureza do cotidiano, é algo palpável quando analisarmos mais de perto o nível de descontentamento e as variadas formas desta se manifestar publicamente nos protestos de rua.

\section{Cidadania e participação: desafios para a construção do novo na história}

Quando alguém fala de cidadania, começamos a pensar de que processos políticos e sociais estariam se referindo. Pois não há um sentido único, ou uma concepção consensual de cidadania. Mas, a relação entre cidadania e participação 
social e política já denota uma determinada concepção de democracia e organização político-social.

$\mathrm{Na}$ discussão sobre o que é cidadania, despontam várias concepções diferentes. Para a finalidade dessa reflexão seguiremos a distinção conceitual adotada por Santos (2008). Para este autor, numa perspectiva do liberalismo clássico, cidadania diz respeito aos direitos civis e políticos do cidadáo pertencente a uma determinada Nação, ou País, do qual este é membro e goza plenamente de seus direitos políticos. Para essa noção de cidadania, a existência do Estado moderno é fator determinante para a garantia do exercício da cidadania das pessoas que nele se constituem como cidadãos. Já na perspectiva neoliberal hoje pretensamente hegemônica, ser cidadão é ter as condiçóes necessárias para participar livremente de uma sociedade organizada pelo mercado global. Ou, dito de modo mais direto, cidadão para a visão neoliberal é quem tem as condiçóes de uma renda suficiente para adquirir bens e serviços ofertados em uma escala global via o comércio mundial. Assim, as pessoas que podem comprar em uma escala mundial os bens de consumo ofertados nos mercados cada vez mais globalizados são consideradas "cidadãos do mundo" pelo poder econômicopolítico dominante.

Mas, para além dessas duas concepções, descritas acima, despontam a noção de cidadania numa perspectiva do Estado de bem estar social e, também, a concepção de cidadania numa perspectiva da democracia participativa e construção social emancipatória. Para a Social Democracia (durante muito tempo no poder nas cidades europeias), ser cidadão é participar da vida política ativa e ter garantido pelo estado as condiçôes mínimas de uma vida digna com seguridade social. Já numa perspectiva da democracia participativa, cidadania é um processo histórico de construção política e social que requer o envolvimento de todos os cidadãos (SANTOS, 2007) nas decisões mais importantes da cidade e do país. Cada cidadão precisa se manter ativo na vida pública e participar no debate público sobre as decisões políticas definidoras da organização social e do futuro de um povo.

Essas diferentes concepçôes de cidadania não existem de forma pura nas sociedades concretas. Cada nação, em seus diferentes contextos sociais e políticos, passam por uma forma predominante no exercício de construção da cidadania relativo ao modelo político vigente e, dessa forma, tem uma forma mais definidora que predomina em cada contexto. Mas, o que já foi construído nunca é definitivo e, portanto, poderá sofrer mudanças.

$\mathrm{Na}$ relação entre cidadania e participação política e social em que os jovens são hoje protagonistas, a cidadania participativa e emancipatória parecem constituirse no horizonte que emerge para a construçáo de novas propostas de sociedade. Pois, 
o que desponta desse movimento insurgente é, por um lado a descrença diante das velhas estruturas políticas, a exemplo dos partidos políticos como instituições clássicas da democracia representativa. Mas, também emerge dessas mobilizaçóes lideradas pelos jovens nas ruas, a cobrança muito clara e forte de viabilizarmos novas formas de participação política, que deem abertura mais direta para os cidadãos atuarem na vida pública.

Nesse contexto, os jovens constituem-se enquanto novidade histórica frente as demais gerações e às tradições culturais que se pretendem hegemônicas, pois enquanto nova geraçáo a juventude está fora da lógica estruturante do mundo já instituído. Entretanto, surge o desafio de saber interpretar o movimento da história para entender o sentido do "novo" e/ou do inédito viável que está sendo gestado a partir dos processos culturais protagonizados pela juventude atual, a exemplo das manifestações organizadas pelas redes sociais.

Hoje estão em andamento alguns processos culturais inovadores, com novos sentidos, politicamente rebeldes, tornando-se importantes para o processo de libertação humano-social. Tais processos culturais, que são protagonizados geralmente por jovens, estão sendo gestados a partir de novas práticas sociais, que brotam de iniciativas locais, tornam-se movimentos de lutas e propostas alternativas, identificadas com valores coerentes com o futuro sustentável de nosso planeta. Há, nesse sentido, um acúmulo de vivências, experiências e lutas das organizaçôes juvenis que se transformaram no autêntico "jeito de ser" do jovem que é esperançoso diante do futuro. Nesse sentido podemos destacar vários movimentos protagonizados pela juventude: a Massa Crítica (uma forma de colocar a discussão do transporte público e da relaçáo sustentável com a cidade a partir do deslocamento urbano através do uso da bicicleta); o Passe Livre (jovens estudantes pleiteando o passe livre no transporte urbano para a populaçáo toda); o Bloco de Lutas (que congrega várias iniciativas dos jovens articulando-se em rede para o debate das questóes mais imediatas dos jovens hoje).

Portanto, hoje vivenciamos no Brasil e em vários outros países, um horizonte político e social rico e fecundo em iniciativas políticas. Esse tempo presente é protagonizado pelas diferentes formas de organização dos jovens que se mobilizam, ocupando as ruas e participando do debate público na cidade sobre o futuro que desejam para a sociedade. Essas iniciativas dos jovens estão servindo de ponto de partida para as lutas futuras de construçáo de uma democracia efetiva e de alta intensidade (SANTOS, 2008).

Entretanto, o desafio ainda é enorme se considerarmos os entraves concretos da realidade social que precisamos transpor para efetivamente nos constituirmos em 
cidadãos livres e emancipados no amplo sentido desses termos. Para isso, faz-se necessário cultivarmos coletivamente o horizonte de nosso tempo histórico, que implica a vivência intersubjetiva do sonho e da esperança em um mundo mais humanizado (FREIRE, 1994), onde todos tenham condições de ser e viver com dignidade. $\mathrm{O}$ ponto de partida para essa utopia coletiva deve ser a realidade social e política que nos constitui hoje. A partir daí será possível construir novos caminhos, para a vida humana em sociedade, superando as limitaçôes de uma cultura e um conjunto de sistemas já instituídos que excluem e controlam o dinamismo das forças juvenis.

O nosso futuro está diretamente relacionado com a reinvenção dos modelos de vida, das formas de organização social, dos sistemas de controle que geralmente são reproduzidos como uma verdade plena. E, nesse sentido, um dos grandes desafios da atualidade, diante do ufanismo dos sistemas financeiros e dos mercados globalizados, é a desalienação da existência humana hoje fortemente controlada, e até mesmo asfixiada, pelo mundo dos sistemas burocratizantes, que nos desumanizam a todos. Esse processo emancipatório fundamenta-se na esperança diante do futuro capitaneada pelas geraçóes jovens, que são o grande potencial para reinventar as formas de viver em sociedade, superando as crises que historicamente nos atingem e desenvolvendo o potencial de humanização (FREIRE, 1996) intrínseco à própria vocação da espécie humana.

\section{Considerações}

Para finalizar nossa reflexão sobre juventude, educação e participação social e política, analisando contextos históricos diferenciados para tencionar o momento presente, buscamos apontar alguns aspectos centrais que se mostraram mais significativas. Destacamos a seguir os pontos centrais:

Em primeiro lugar destacamos que a democracia representativa poderá ser dialeticamente superada por um sistema misto entre ela própria e a democracia direta ${ }^{9}$ onde a sociedade civil tenha mecanismos de controlar o Estado e também o Mercado (DEMO, 1993). A riqueza e qualificação da esfera política de uma sociedade estão em seu grau de politização que se materializa na participação ativa dos cidadãos nas

\footnotetext{
${ }^{9}$ Essa experiência já está em curso no Brasil em muitas administraçôes municipais e mais recentemente em alguns Estados, que adotam a organização da população (via conselhos, comissões, representatividades, etc.) como forma de controle público do poder Estatal. Por exemplo, o orçamento participativo em Porto Alegre, e agora no atual governo estadual do Rio Grande do Sul, a Gestão Democrática da Escola Cidadã, o projeto de Eurocidades ou Mercocidades, além de tantas experiências positivas que estão em andamento nesse sentido.
} 
decisões e atividades públicas. É a sociedade civil, constituída por cada cidadão (enquanto sujeito social), quem deve decidir os rumos de sua história e não apenas escolher representantes que seriam os "iluminados" para decidir o futuro de todos e que, via de regra, decidem os rumos da sociedade a partir de seus gabinetes sem diálogo com o povo.

Outro aspecto a destacar é a reinvenção do poder, que passa pela reinvenção da política, principalmente, na superação do modelo de democracia representativa hoje vigente. Esse processo requer uma posição radical de desconstrução do que está envelhecido e ultrapassado, mas que ainda conserva as antigas relaçóes de poder via assistencialismo, troca de favores e composiçóes entre lideranças e partidos políticos. Mas, para além da desconstrução, é necessário construir novas formas de organização política, criando alternativas para que possamos trilhar novos caminhos que possibilitem uma democracia autêntica porque construída com a participaçâo de todos os sujeitos sociais e políticos, discutindo seus próprios problemas e interferindo na realidade rumo à transformação social. Estamos em um momento histórico, cuja tarefa central é a construção de uma DEMOCRACIA RADICAL, na qual todos nos sintamos representados, e que compatibilizem Igualdade e Liberdade, Unidade e Multiplicidade, Diversidade e Diferença, Direitos das Maiorias e Direitos das Minorias (MEJÍA, 1996, p.73).

Esse processo de superaçáo do atual estágio da democracia representativa requer caminhos de comunicação social que sirvam de alternativa ao grande poder da mídia, que está intimamente sintonizado com o controle do poder político pelas classes dominantes. A internet, que dá suporte às redes sociais utilizadas pelos jovens em sua rebeldia e proposição do novo na política e na agenda da sociedade, pode servir como alternativa à mídia conservadora. A partir das manifestaçóes lideradas pelos jovens a partir de junho de 2013 a classe política no Brasil lançou a promessa de uma reforma nas instituições que visavam ampliar a participação da sociedade nas decisóes políticas. Pois essa foi uma das reivindicaçôes dos protestos de rua.

Portanto, a mobilização social rumo à transformação da política e das estruturas sociais hegemônicas requer o diálogo, o debate e a permanente comunicaçáo aberta e democrática entre os sujeitos políticos que aspiram pela superação de todas as formas de opressão social. Nesse sentido, as formas alternativas de comunicação são instrumentos importantes que contribuem para facilitar a mobilização popular e colocar o "bloco na rua". Mas isso não é suficiente. Eis, então, uma questão que segue provocando nossas leituras e análises da realidade política 
atual: o que efetivamente possibilitaria mobilizar as pessoas, os movimentos sociais e os sujeitos políticos para uma agenda de luta mais consistente e articulada em redes de organização popular? Que cenários podemos projetar para o futuro próximo das mobilizações de rua no Brasil, que foram protagonizadas pelos jovens em meados de 2013 ?

Tais questóes, acima apontadas, necessitam serem aprofundadas pelo campo das ciências sociais, cientistas políticos e da educação, pois é fenômeno recente que revela o potencial das redes sociais para mobilizar, especialmente a juventude. Mas, ao mesmo tempo, a forma de organizaçáo via redes sociais, demonstra grande fragilidade em termos de continuidade e a representatividade das lideranças.

- Jaime José Zitkoski é Professor na Faculdade de Educação da Universidade Federal do Rio Grande do Sul (FACED/UFRGS) nos cursos de licenciaturas e na Pós-Graduação em Educação. E-mail: 00086365@ufrgs.br.

- Lúcio Jorge Hammes é Professor da Universidade dos Pampas (UNIPAMPA) e na Pós-Graduação em Educação da UNIPAMPA. Email:1uciojh@gmail.com.

\section{Referências}

ABRAMO, Helena W. Consideraçóes sobre a tematização social da juventude no Brasil. Juventude e Contemporaneidade. Revista Brasileira de Educação. São Paulo: ANPED, n. 5 e 6, 1997, p. 25-36. ARNOLD, Patrícia. Depoimento [jul. 2004]. Entrevistador: Hammes, LJ. Universidade do Vale do Rio dos Sinos, São Leopoldo, 2004.

BAQUERO, Marcello (Org). A Lógica do Processo Eleitoral em Tempos Modernos: novas perspectivas de análise. Porto Alegre/Canoas: Editora da Universidade/UFRGS/Centro Educacional La Salle de Ensino Superior, 1997.

DEMO, Pedro. Pobreza Politica. São Paulo: Cortez, 1993.

FREIRE, Paulo. Pedagogia da autonomia: saberes necessários à prática educativa. São Paulo: Paz e Terra, 1996. . Pedagogia da Esperança. Rio de Janeiro: Paz e Terra, 1994. Pedagogia do Oprimido. São Paulo: Paz e Terra, 1993.

GADOTTI, Moacir. Escola cidadá. São Paulo: Cortez, 1994

GARCIA, Viviane. Depoimento [jul. 2004]. Entrevistador: Hammes, LJ. Universidade do Vale do Rio dos Sinos, São Leopoldo, 2004. 
GERHART, Camila. Depoimento [jul. 2004]. Entrevistador: Hammes, LJ. Universidade do Vale do Rio dos Sinos, São Leopoldo, 2004.

GOMES, Sérgio. Depoimento [jul. 2004]. Entrevistador: Hammes, LJ. Universidade do Vale do Rio dos Sinos, São Leopoldo, 2004.

HAMMES, Lúcio Jorge. Aprendizados de convivência e a formação de capital sociat: um estudo sobre grupos juvenis. 2003, f. 2005. Tese (Doutorado em Educação) - Universidade do Vale do Rio dos Sinos, São Leopoldo, 2005.

LIBERATO, Leo Vinicius Maia. Expressóes contemporâneas de rebeldia: poder e fazer da juventude autonomista. 2006, f. 265. Tese (Doutorado em Sociologia Política)-. Universidade Federal de Santa Catarina. Florianópolis, 2006.

KRAUSKOPF, Dina. Dimensiones críticas en la participación social de las juventudes. In: BALARNDINI, Sergio (coord.). La Participación social y Política de Los Jovenens en el Horizonte del Nuevo Siglo. Buenos Aires: CLASCO, 2000, pp. 119-134.

MELO, Gabriel: Depoimento [jul. 2004]. Entrevistador: Hammes, LJ. Universidade do Vale do Rio dos Sinos, São Leopoldo, 2004.

MEJÍA, Marco R. Transformação social. São Paulo: Cortez, 1996.

PARO, Vitor. Gestão democrática da escola Pública. Caderno temático no 1, Constituinte Escola. Porto Alegre: CORAG. SE/RS, 2000.

PUTNAM, Robert D. Comunidade e democracia: a experiência da Itália moderna. Rio de Janeiro: Fundação Getúlio Vargas, 1996.

RODRÍGUEZ, Melania Portilla. Juventude Rurat: Construyendo la ciudadanía de los territorios rurales (Documento Borrador de Tabalho). Instituto Interamericano de Cooperación para la Agricultura (IICA) - sede central, Marzo del 2003. Disponível em: $<$ http://www.ipadej.org/virtual/pluginfile.php/115/mod_resource/content/1/juventd\%20riral\%20 y\%20cuidadania\%20-\%20IICA.PDF>. Acesso em mai. 2014.

SANTOS, Boaventura de S. A Gramática do Tempo: para uma nova cultura política. São Paulo: Cortez, 2008.

. Renovar a Teoria Crítica e Reinventar a Emancipação Social. São Paulo: Boitempo, 2007.

SCHWARTZ, Peter. A Arte da Previsão: planejando o futuro em um mundo de incertezas. Trad. de Alana Madureira. São Paulo: Scrita, 1995.

SCHMIDT, Marlon: Depoimento [jul. 2004]. Entrevistador: Hammes, LJ. Universidade do Vale do Rio dos Sinos, São Leopoldo, 2004.

SPÓSITO, Marilia P.; CORTI, Ana Paula de O. A Pesquisa sobre juventude e os temas emergentes. In: SPOSITO, Marilia P. (Coord). Juventude e escolarização (1980-1998). Brasília: MEC/Inep/Comped, 2002. p. 203-221.

UN. United Nations. World Youth Report 2005: Young people today, and in 2015. Out. 2005. Disponível em: <http:/www.un.org/esa/socdev/unyin/documents/wyr05book.pdf>. Acessado em: 15 abr. 2014. 

